\title{
Plant Regeneration via Somatic Embryogenesis from Leaf and Floral Explants of 'Chancellor' Wine Grape
}

\author{
Richard M.S. Mulwa ${ }^{1}$, Margaret M.A. Norton ${ }^{2}$ and Robert M. \\ Skirvin $^{2}$
}

Egerton University, Department of Crops, Horticulture and Soils, P.O. Box 536, Egerton, Kenya

Key words: Chancellor grape, Regeneration, Somatic embryogenesis

\begin{abstract}
Abundant embryogenic callus was obtained from leaf and floral explants of "Chancellor" grape by continuous culture for 12 weeks on Nitsch and Nitsch basal medium supplemented with $9 \mu \mathrm{M} 2,4$-D + $17 \mu \mathrm{M}$ IASP + either $1 \mu \mathrm{M}$ BA or $1 \mu \mathrm{M}$ TDZ (ECIM) in darkness. They were successfully maintained by a five to six week subculture interval on NN medium containing $2 \mu \mathrm{M} 2$, 4-D + $0.2 \mu \mathrm{M}$ TDZ + $4 \mu \mathrm{M}$ IASP (LTMM). Near synchronous embryo developed from embryogenic callus on medium containing $10 \mu \mathrm{M}$ IASP $+8 \mu \mathrm{M} N O A+1 \mu \mathrm{M}$ $\mathrm{TDZ}+1 \mu \mathrm{M}$ ABA + $2.5 \mathrm{~g} / \mathrm{l} \mathrm{AC}(\mathrm{EDMM})$. Individually separated somatic embryos were germinated on both $\mathrm{NN}$ and half strength of MS containing 0.5 $\mu \mathrm{M}$ BA $+0.025 \mu \mathrm{M}$ NAA, respectively; normal plantlet conversion from embryos was low (35\%). Whole fruiting plants were obtained. Aberrant embryo development was characterized by failure to form functional shoot meristems following the initial cotyledon expansion during germination. These observations indicate that the embryo conversion stage of the regeneration is difficult and remains a limiting factor requiring more empirical experimentation for improvement in grape tissue culture.
\end{abstract}

\section{Introduction}

The grapevine (Vitis spp.) is the third most important fruit crop in the world after banana and citrus. Commercial production in different parts of the world is limited to a few outstanding regional cultivars. Genetic improvement of these cultivars through conventional breeding is greatly hampered by long generation

1Author for correspondence: <rmulwa@egerton.ac.ke> or <risamuk@gmail.com>. 2Department of Natural Resources and Environmental Sciences, University of Illinois at Urbana-Champaign, 258 ERML Building, 1201 W. Gregory Dr. Urbana, IL 61801, USA. 
times, rampant polyploidy and the highly heterozygous nature of the crop. The application of molecular techniques could be an attractive alternative in the improvement of specific grape cultivars if highly efficient and effective regeneration systems were available.

Somatic embryogenesis (SE) is an important tool in making genetic improvements using molecular and cellular techniques including genetic transformation. SE was first reported in grapevines by Mullins and Srinivasan (1976) from the nucellar tissues of unfertilized ovules. Since then SE has been achieved using a variety of explants including zygotic embryos (Emershad and Ramming 1994), ovaries (Gray and Mortensen 1987, Motoike et al. 2001), leaves and stems (Krul and Worley 1977, Robacker 1993), anthers (Popescu 1996) and tendrils (Salunkhe et al. 1997).

Although leaf explants are an obviously attractive starting material for SE investigations, overall their efficiency for becoming embryogenic remains low. In contrast, in most grape species, reproductive organ explants such as anthers (Faure 1990, Altamura et al. 1992), ovules (Srinivasan and Mullins 1980) and zygotic embryos (Stamp and Meredith 1988) have been employed with much greater success.

In this paper methods to induce embryogenic callus from leaf and floral explants of 'Chancellor' wine grape and the development of a plant regeneration system via somatic embryogenesis on agar-based media are reported. The 'Chancellor' wine grape is a complex interspecific French-American hybrid developed in the late 1800s and introduced into the United States in the 1940s (Brooks and Olmo 1997). The vines are vigorous, high yielding and well adapted to the growing microclimates of the Midwestern USA. 'Chancellor' wine is described as dry, heavy bodied with a rich plum-cedar aroma and a dense rubyviolet color. It is also frequently used in blends (Brooks and Olmo 1997).

\section{Materials and Methods}

Two explants used in this study were floral buds of 'Chancellor' grape collected 10 to 15 days before anthesis (DBA) from greenhouse-forced cuttings taken in mid-winter and young leaves (third leaf from the tip) collected from the field in early Spring. Freshly harvested flower buds were surface disinfested by washing in Tween $20^{\mathrm{R}}$ detergent solution followed by treatment with $2.5 \%(\mathrm{v} / \mathrm{v})$ Clorox bleach $(5.25 \% \mathrm{NaOCl})+0.01 \%$ Tween $20^{\mathrm{R}}$ for $10 \mathrm{~min}$. Leaves were disinfested by washing as described above and treatment with $1 \%$ bleach for $15 \mathrm{~min}$. All plant materials were rinsed four times in sterile distilled water. Floral explants were dissected to recover the individual ovaries and associated receptacle tissues; leaves were sectioned into approximately $1 \mathrm{~cm}^{2}$ pieces including the midrib. Both explant types were placed on various embryogenic culture initiation media. 
Embryogenic callus induction was tested on NN basal salts medium (Nitsch and Nitsch 1969) containing $30 \mathrm{~g} / \mathrm{l}$ sucrose, $100 \mathrm{mg} / \mathrm{l}$ myo-inositol, $800 \mathrm{mg} / \mathrm{l}$ casein hydrolysate and gelled with $2.5 \mathrm{~g} / \mathrm{l}$ phytagel (Sigma-Aldrich, USA). Various growth regulators and combinations were tested as follows: (a) 2, 4-D (9 $\mu \mathrm{M})$; (b) IASP $(17 \mu \mathrm{M})$; (C) 2, 4-D $(9 \mu \mathrm{M})+$ IASP $(17 \mu \mathrm{M})$; (d) 2, 4-D $(9 \mu \mathrm{M})+$ IASP $(17 \mu \mathrm{M})+\mathrm{BA}(1 \mu \mathrm{M})$ and (e) 2, 4-D $(9 \mu \mathrm{M})+\operatorname{IASP}(17 \mu \mathrm{M})+\operatorname{TDZ}(1 \mu \mathrm{M})$. A control treatment without growth regulators was also included. All media were adjusted to $\mathrm{pH} 5.6$ before autoclaving and growth regulators were added after autoclaving as stock solutions $(1 \mathrm{mg} / \mathrm{ml})$ in DMSO. The experimental set up was a $2 \times 2 \times 6$ factorial in a completely randomized design (CRD) with four replicated plates for each treatment and each plate containing 20 explants. Explants were assessed for embryogenic callus induction following a continuous dark incubation for 12 weeks in a culture room maintained at $25 \pm 2{ }^{\circ} \mathrm{C}$. To select appropriate callus induction media and best explant source for further experimentation, mean percentage embryogenic callus induction data were computed.

Determination of a suitable long-term embryogenic callus maintenance medium and an appropriate subculture interval, embryogenic callus induced on the selected medium was used. Callus scoops, approximately $3 \mathrm{~mm}$ in diam, were transferred to basal $\mathrm{NN}$ medium as described above but with different growth regulator regimes. This experiment tested the effect of two auxins ( $2 \mu \mathrm{M}$ 2,4-D or $\beta$-naphthoxyacetic acid (NOA, $2 \mu \mathrm{M}$ )) in combination with $0.2 \mu \mathrm{M}$ BA or $0.2 \mu \mathrm{M}$ TDZ) and with or without the addition of IASP $(4 \mu \mathrm{M})$ on growth and the embryogenic status of the callus. A control treatment without growth regulators was also included. Cultures were incubated in the dark for five weeks as described previously. A CRD with three replicate plates per treatment, each containing ten explants was used. Growth assessments at the end of this period included measuring the diameter of calli at the surface of contact with the medium and determining the number of embryos (if any) formed per callus. The tendency of callus to revert to a non-embryogenic state was also assessed. The growth regulator combination that produced the largest callus diameter, the lowest number of embryos per callus as well as showing the lowest tendency for the callus to revert to the non-embryogenic state was selected for long-term embryogenic callus maintenance. This medium was designated long-term embryogenic callus maintenance medium (LTMM).

To determine a suitable subculture interval for embryogenic callus maintenance, callus was cultivated in LTMM and assessed one time after four, five, six, or seven weeks. Each interval included four replicate plates containing ten calli each. Data on callus growth, embryo formation and preservation of 
embryogenic status at the end of each of these intervals was determined as described previously.

Embryogenic callus (approx. $5 \mathrm{~mm}$ in diam) grown on LTMM for five to six weeks was used. Calli were transferred into Petri plates (100 mm diam) containing $30 \mathrm{ml}$ of $\mathrm{NN}$ basal medium supplemented with various combinations of growth regulators (IASP $(10 \mu \mathrm{M})$, NOA $(8 \mu \mathrm{M})$, BA $(1 \mu \mathrm{M})$, and abscisic acid $(\mathrm{ABA}, 1 \mu \mathrm{M})$ ) in the presence or absence of $2.5 \mathrm{~g} / 1$ activated charcoal (AC, Darco $\mathrm{S} 51)$. Details of the growth regulator combinations used in these experiments are displayed in Table 4 To each of these media, $50 \mathrm{~g} / \mathrm{l}$ of polyethylene glycol (PEG, Amresco-OH) was added before autoclaving. Plates were incubated in darkness for two weeks under the previously described conditions then transferred to a 16 hr photoperiod provided by cool-white fluorescent lamps emitting approximately $130 \mu \mathrm{mol} / \mathrm{m}^{2} / \mathrm{s}$ of photosynthetically active radiation (PAR) at the surface of the plates. The experiment was set up as a CRD and each growth regulator combination treatment was replicated in three plates, each containing ten embryogenic callus masses. The number of calli with mature embryos and the total number of embryos formed in each plate was assessed four to five weeks later.

To study somatic embryo germination and plantlet development, individual mature embryos, approx. $2 \mathrm{~mm}$ long, were picked from clusters on embryo development medium, air-dried on sterile filter papers for $15 \mathrm{~min}$ and transferred into germination and conversion test media - either half strength of MS or NN medium containing $30 \mathrm{~g} / \mathrm{l}$ sucrose, $100 \mathrm{mg} / \mathrm{l}$ myo-inositol, Staba vitamins (Staba 1969) and $2.5 \mathrm{~g} / \mathrm{l}$ phytagel. Media $\mathrm{pH}$ was adjusted to 5.6 before autoclaving. Three growth regulator regimes (control; $0.4 \mu \mathrm{M}$ BA $+0.5 \mu \mathrm{M}$ Naphthalene acetic acid (NAA); or $0.5 \mu \mathrm{M}$ BA + $0.025 \mu \mathrm{M}$ NAA) were tested in the presence or absence of $2.5 \mathrm{~g} / \mathrm{l} \mathrm{AC}$ in the media. The experiment was set up as a $2 \times 2 \times 3$ factorial arrangement in a CRD with each medium treatment being replicated in three plates containing ten embryos each; the trial was repeated three times. Cultures were incubated in the dark for seven days then transferred to a lighted culture room with the photoperiod described previously. Germination counts were taken after three weeks; plantlet development was assessed six weeks after exposure to light, respectively. Developing plantlets were transferred to baby food jars $(100 \times 50 \mathrm{~mm})$ containing $40 \mathrm{ml}$ of half strength of MS supplemented with $0.5 \mu \mathrm{M}$ BA $+0.025 \mu \mathrm{M}$ NAA and grown until they were ready for transfer into soil.

Data from all experiments were subjected to ANOVA using the SAS General Linear Model (Proc GLM) procedure. Mean separations were carried out by the DMRT; significant interactions were analyzed with the 'Proc mixed' procedure in the SAS statistical package (SAS Institute Inc. 1990). 


\section{Results and Discussion}

Callus formation was observed on both leaf and ovary explants two weeks after explanting to media. In both cases callus developed on the cut surfaces and grew rapidly to cover most of the original explant. Significant variations were observed in the ability of explants to develop callus and initiate embryogenesis (Table I). Callus formation by ovary explants was observed on all media tested, including controls (no growth regulators); leaf explants formed callus only in media containing combinations of growth regulators (Table 1). The highest callus induction (100 and $92.5 \%$, for ovary and leaf explants, respectively) was observed on medium supplemented with a combination of $9 \mu \mathrm{M} 2,4-\mathrm{D}, 17 \mu \mathrm{M}$ IASP and 1 $\mu \mathrm{M}$ BA. No callus was formed on leaves explanted on media with IASP only. Overall, ovary explants displayed a higher potential to produce embryogenic callus than leaf explants (Table 1).

Table 1. Effect of growth regulator combinations on the induction of callus and initiation of embryogenesis in ovary and leaf explants of 'Chancellor' grapes in vitro.

\begin{tabular}{|c|c|c|c|c|c|c|c|}
\hline \multicolumn{4}{|c|}{ Growth regulators $(\mu \mathrm{M})$} & \multicolumn{2}{|c|}{$\%$ callus formation } & \multicolumn{2}{|c|}{ \% embryogenesis } \\
\hline \multicolumn{2}{|c|}{ Auxins } & \multicolumn{2}{|c|}{ Cytokinins } & \multirow[t]{2}{*}{ Ovary } & \multirow[t]{2}{*}{ Leaf } & \multirow[t]{2}{*}{ Ovary } & \multirow[t]{2}{*}{ Leaf } \\
\hline $2,4-\mathrm{D}$ & IASP & BA & TDZ & & & & \\
\hline 0 & 0 & 0 & 0 & $10.0 \mathrm{c}$ & $0.0 \mathrm{c}$ & $0.0 \mathrm{~b}$ & $0.0 \mathrm{c}$ \\
\hline 0 & 17 & 0 & 0 & $47.5 \mathrm{~b}$ & $0.0 \mathrm{c}$ & $0.0 \mathrm{~b}$ & $0.0 \mathrm{c}$ \\
\hline 9 & 0 & 0 & 0 & $78.75 a$ & $80.0 \mathrm{ab}$ & $6.25 b$ & $1.25 c$ \\
\hline 9 & 17 & 0 & 0 & $78.75 a$ & $67.5 \mathrm{~b}$ & $0.0 \mathrm{~b}$ & $8.75 b c$ \\
\hline 9 & 17 & 0 & 1 & $81.25 a$ & $88.75 a$ & $41.25 \mathrm{a}$ & $15.0 \mathrm{~b}$ \\
\hline 9 & 17 & 1 & 0 & $100 \mathrm{a}$ & $92.5 \mathrm{a}$ & $55.0 \mathrm{a}$ & $26.25 \mathrm{a}$ \\
\hline
\end{tabular}

Means within columns followed by the same letter series are not significantly different by DMRT at $\mathrm{p} \leq 0.05$.

To maintain cultivar identity, it is important that plants regenerated from ovary explants be of somatic (not meiotic) origin. Barring mutation, regenerants from leaf explants should be identical to the parents. Shoots regenerated from ovary tissues, as was the case in the present study, could arise from either somatic or meiotic tissues resulting in haploids or double haploids, or even from zygotic embryos that have already developed in the ovaries. However, histological studies of grape somatic embryogenesis from reproductive organs have shown that embryogenesis has always originated from somatic tissues in these organs. Nakano et al. (2000) examined the callogenesis and adventitious embryogenesis in immature ovary cultures of several Vitis vinifera cultivars and concluded that embryogenesis originated exclusively from parenchyma cells of the ovary wall and receptacle tissues. 
In this study the callus produced by explants initially was whitish-grey, friable and fast growing, similar to that reported by Motoike et al. (2001). Preliminary trials had shown that serial transfer of this callus to fresh media every four to five weeks only encouraged its rapid proliferation with no observable embryogenic tendencies. In subsequent experiments the original explants with their developing calli were maintained in the same media and culture vessel for up to 12 weeks. At the end of this period calli were turning dark brown, an indication of non viable and autolytic tissue (Gianazza et al. 1992). However, the edges of some calli exhibited compact, granular, yellowishwhite clusters of small almost isodiametric proembryonic masses typical of embryogenic callus (Fig. 1a). These calli became the source of the present embryogenic cell lines.

In the present study, the highest embryogenic competency levels (55 and $26 \%$ for ovary and leaf explants, respectively) were recorded on medium supplemented with $9 \mu \mathrm{M} 2$, 4-D + $17 \mu \mathrm{M}$ IASP with either $1 \mu \mathrm{M}$ BA or $1 \mu \mathrm{M}$ TDZ (Table 1). BA medium was chosen for subsequent studies and named it the embryogenic callus initiation medium (ECIM).

Growth regulator combinations also play a role in the induction of somatic embryogenesis in grapes. Previous studies have reported that a synergistic effect of different auxins, particularly 2, 4-D and IASP, is an important factor in the initiation of embryogenesis in two cultivars of Vitis labrusca (Motoike et al. 2001) and in the re-initiation of embryogenesis from mature somatic embryos of Vitis vinifera (Perl et al. 1995). In this study no such synergism was demonstrated. However, to induce the highest rates of embryogenesis in both floral and leaf explants there seemed to be a requirement for the inclusion of a cytokinin (either BA or TDZ) in addition to the two auxins, 2,4-D and IASP, (Table 1).

Motoike et al. (2001) reported that the ECIM was not suitable for long term maintenance of the embryogenic state due to the high levels of growth regulators used in the induction process. According to Martinelli and Gribaudo (2001) subculturing induced embryogenic callus on the same medium and culture conditions can trigger it to develop embryos at the expense of embryogenic callus leading to a drastic reduction or loss of the primary embryogenic callus cultures. To ensure a continual supply of regenerative callus in the present study, an appropriate embryogenic callus maintenance medium and subculture interval had to be established. To this end, embryogenic callus produced in the induction stage was cultivated in NN medium containing various combinations of $2 \mu \mathrm{M} 2$, 4-D or $2 \mu \mathrm{M}$ NOA with $0.2 \mu \mathrm{M}$ BA or $0.2 \mu \mathrm{M}$ TDZ in the presence or absence of $4 \mu \mathrm{M}$ IASP. The objective was to select a growth regulator combination that would promote optimal embryogenic callus growth without inducing precocious embryo development and to use the selected medium to 
determine a suitable subculture interval to maintain the callus. A combination of $2 \mu \mathrm{M} 2,4-\mathrm{D}+0.2 \mu \mathrm{M}$ TDZ $+4 \mu \mathrm{M}$ IASP produced the best proliferating callus in terms of growth (13.3 mm diam), lowest percentage (10) of reversion to the nonembryogenic state and significantly lowest number of embryos formed per callus (0.7) (Table 2, Fig. 1b). When TDZ was replaced with BA there were no significant differences in the final callus sizes or percentage non-embryogenic tendencies. However, substituting BA for TDZ significantly increased precocious embryo development, which was not desirable.

Table 2. Effect of growth regulator combinations on growth and maintenance of embryogenic status of 'Chancellor' callus in vitro.

\begin{tabular}{|c|c|c|c|c|c|c|c|}
\hline \multicolumn{5}{|c|}{ Growth regulator combinations $(\mu \mathrm{M})$} & \multirow{3}{*}{$\begin{array}{c}{ }^{*} \text { Mean callus } \\
\text { diameter } \\
(\mathrm{mm})\end{array}$} & \multirow{3}{*}{$\begin{array}{l}* \% \text { non- } \\
\text { embryogenic } \\
\text { callus }\end{array}$} & \multirow{3}{*}{$\begin{array}{c}{ }^{*} \text { Mean number } \\
\text { of embryos per } \\
\text { callus }\end{array}$} \\
\hline \multicolumn{3}{|c|}{ Auxins } & \multicolumn{2}{|c|}{ Cytokinins } & & & \\
\hline $2,4-\mathrm{D}$ & NOA & ISAP & BA & TDZ & & & \\
\hline 0 & 0 & 0 & 0 & 0 & $4.3 \mathrm{c}$ & $0.0 \mathrm{c}$ & $0.0 \mathrm{~b}$ \\
\hline 0 & 2 & 0 & 0 & 0.2 & $11.0 \mathrm{~b}$ & $100.0 \mathrm{a}$ & $0.0 \mathrm{~b}$ \\
\hline 0 & 2 & 0 & 0.2 & 0 & 15.0a & 100.0a & $0.0 \mathrm{~b}$ \\
\hline 0 & 2 & 4 & 0.2 & 0 & $13.0 \mathrm{ab}$ & 93.3a & $0.0 \mathrm{c}$ \\
\hline 0 & 2 & 4 & 0 & 0.2 & $16.0 \mathrm{a}$ & $63.3 \mathrm{~b}$ & $1.0 \mathrm{~b}$ \\
\hline 2 & 0 & 0 & 0.2 & 0 & $16.0 \mathrm{a}$ & 100.0a & $0.0 \mathrm{~b}$ \\
\hline 2 & 0 & 0 & 0 & 0.2 & $10.3 \mathrm{~b}$ & $46.7 \mathrm{~b}$ & $1.0 \mathrm{~b}$ \\
\hline 2 & 0 & 4 & 0.2 & 0 & $11.0 \mathrm{~b}$ & $16.7 \mathrm{c}$ & $4.7 \mathrm{a}$ \\
\hline 2 & 0 & 4 & 0 & 0.2 & $13.3 \mathrm{ab}$ & $10.0 \mathrm{c}$ & $0.7 \mathrm{~b}$ \\
\hline
\end{tabular}

* Means within columns followed by the same letter series are not significantly different by DMRT at $\mathrm{p} \leq 0.05$.

The presence of NOA in any of the media resulted in a significant increase in callus growth with a concomitant loss of embryogenic status. Similar observations were made when a combination of $2 \mu \mathrm{M} 2,4$-D and $0.2 \mu \mathrm{M}$ BA was used (Table 2). Thus, neither NOA alone nor a combination of $2 \mu \mathrm{M} 2,4-\mathrm{D}$ and $0.2 \mu \mathrm{M}$ BA would be suitable growth regulator regimes for long-term maintenance of 'Chancellor' embryogenic callus. On the other hand, placement of embryogenic callus on media without growth regulators did not affect development. However, when the non-proliferating callus in these control treatments was transferred to medium containing $2 \mu \mathrm{M} 2,4-\mathrm{D}+0.2 \mu \mathrm{M} \mathrm{TDZ}+4$ $\mu \mathrm{M}$ IASP a resumption of callus proliferation was observed, indicating a strong requirement for growth regulators to stimulate 'Chancellor' callus growth.

Strategies to maintain the embryogenic competence of grape callus have included regular subcultures in the presence of low levels of auxins, with (Motoike et al. 2001, Perl et al. 1995) or without cytokinins (Martinelli et al. 1993, Motoike et al. 2001) or in growth regulator-free media (Gray and Mortensen 1987). In this study it was found that withdrawal of growth regulators arrested 
cell proliferation. Cultivation in media with low levels of the same growth regulators used in the initiation medium was optimal for the preservation of the embryogenic state as well as for callus growth. On the basis of these results a combination of $2 \mu \mathrm{M} 2,4-\mathrm{D}+0.2 \mu \mathrm{M}$ TDZ $+4 \mu \mathrm{M}$ IASP was selected for a long term maintenance medium (LTMM).

After four to five weeks on LTMM, embryogenic calli began to produce somatic embryos. Embryogenic callus left on LTMM for more than six weeks formed aberrant somatic embryos (Table 3, Fig. 1c). Aberrations included embryos without well-defined radicles or being fused at the radicles or possessing numerous fused cotyledons (Fig. 1e). In some cultures, only white compact masses that did not develop further were formed (Fig. 1d). Similar abnormalities have been reported in embryos obtained from grape anthers (Altamura et al. 1992, Faure et al. 1996). It is therefore concluded that transfer of small scoops of embryogenic callus to new medium every five to six weeks is a better way to maintain 'Chancellor' grape embryogenic callus. Callus left on LTMM more than six weeks yielded aberrant plants.

Table 3. Effect of culture interval on the maintenance of embryogenic status in 'Chancellor' callus in vitro.

\begin{tabular}{cccc}
\hline $\begin{array}{c}\text { Culture period } \\
(\text { weeks })\end{array}$ & $\begin{array}{c}\text { Mean callus diam } \\
(\mathrm{mm})^{\mathrm{z}}\end{array}$ & $\begin{array}{c}\text { Mean No. of calli } \\
\text { with embryos }\end{array}$ & $\begin{array}{c}\text { Mean no. of embryos } \\
\text { per callus }^{\mathrm{z}}\end{array}$ \\
\hline 4 & $8.4 \mathrm{~b}$ & $0.8 \mathrm{~b}$ & $0.32 \mathrm{~b}$ \\
5 & $8.9 \mathrm{~b}$ & $1.0 \mathrm{~b}$ & $0.38 \mathrm{~b}$ \\
6 & $11.7 \mathrm{a}$ & $1.4 \mathrm{~b}$ & $0.68 \mathrm{ab}$ \\
7 & $13.0 \mathrm{a}$ & $3.2 \mathrm{a}$ & $1.12 \mathrm{a}$ \\
\hline
\end{tabular}

${ }^{\mathrm{z}}$ Means are from four replicate plates of ten explants each. Means within columns followed by the same letter series are not significantly different by DMRT at $\mathrm{p} \leq 0.05$.

Although asynchronous embryo development from grape callus is common, especially on solid media (Martinelli and Gribaudo 2001), an ideal regeneration system based on somatic embryogenesis should be synchronized for embryo development.

To study the effects of several growth regulator combinations and the presence or absence of $\mathrm{AC}$ in the medium on embryo development and maturation, a series of experiments were designed. Significant variations were observed among treatments with respect to the numbers of calli forming embryos and the total numbers of embryos formed (Table 4). Overall, nearsynchronous embryo formation was observed within four to five weeks when pro-embryonic masses were cultured in medium supplemented with $10 \mu \mathrm{M}$ $\mathrm{IASP}+8 \mu \mathrm{M} \mathrm{NOA}+1 \mu \mathrm{M} \mathrm{TDZ}+1 \mu \mathrm{M} \mathrm{ABA}+2.5 \mathrm{~g} / \mathrm{l} \mathrm{AC} \mathrm{(Fig.} \mathrm{1f,g).} \mathrm{This} \mathrm{medium}$ was designated embryo development and maturation medium (EDMM). On this medium $87 \%$ of calli formed somatic embryos and the yield of individual mature 


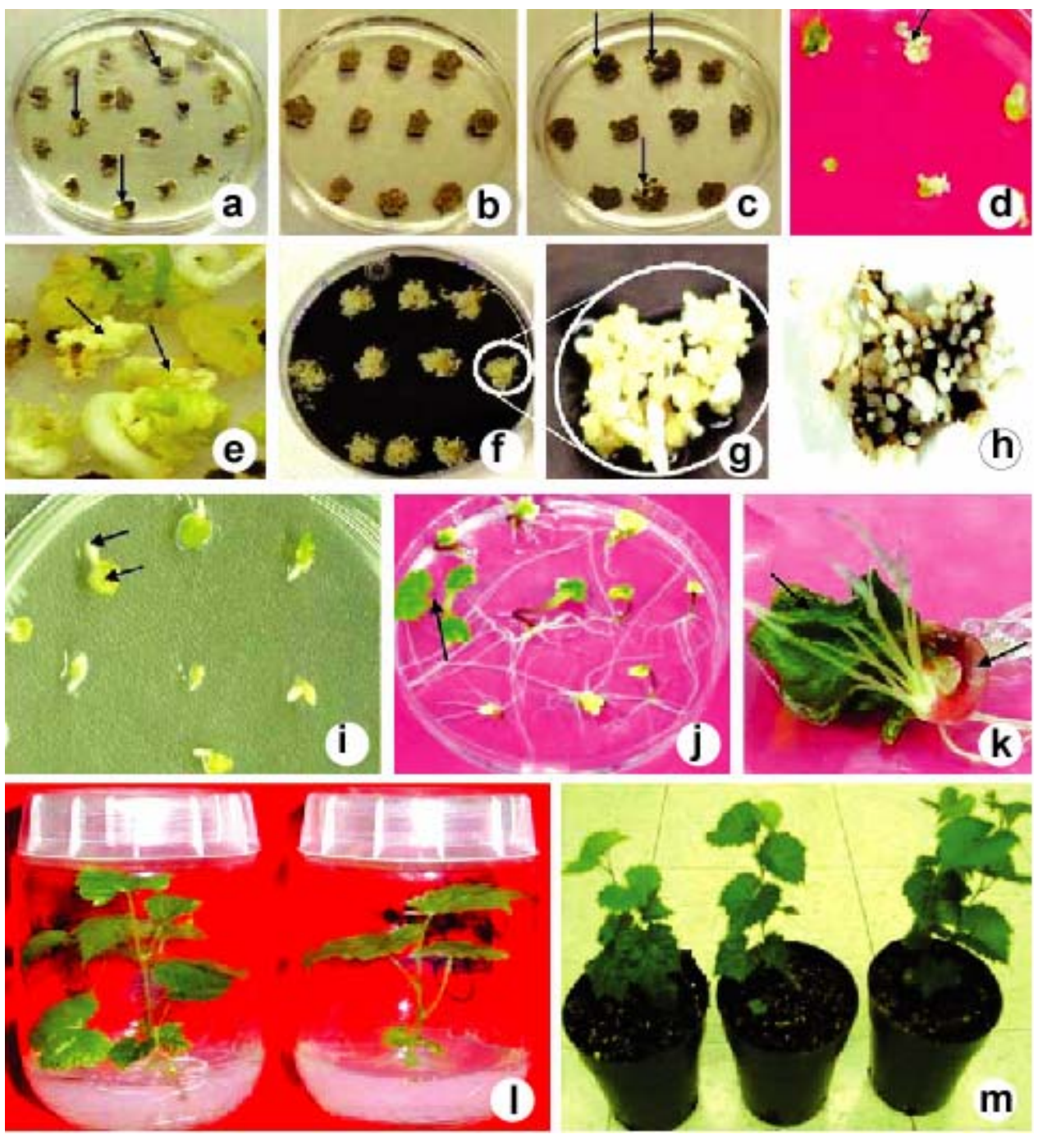

Fig. 1. Embryogenic callus induction, somatic embryo development and plantlet regeneration of 'Chancellor' grape. a. Embryogenic callus formation on ovary explants after 12 weeks culture (arrows). b. Embryogenic callus after 5 weeks in LTMM. c. Embryogenic callus after 7 weeks in LTMM showing precocious embryo development (arrows). d. White compact non-developing structures formed after seven weeks in LTMM. e. Aberrant embryos showing multiple and fused cotyledons. f. Near-synchronous embryo development on EDMM. g. Close-up of mature embryos. h. Asynchronous embryo development in medium without AC. (Photos g \& h courtesy of Daniel Weber, Beckman Institute of Advance Technology, University of Illinois). i. Germinating embryos showing cotyledon expansion, greening and radicle elongation (arrows). j. Plantlet conversion showing extension of growing tips (arrow), root branching and leaf development. k. An aberrant plantlet showing overgrowth of cotyledons and coiling of the hypocotyl. 1. 'Chancellor' plantlets ready for transfer to soil. $\mathrm{m}$. Fully acclimatized plants growing in a greenhouse. 
somatic embryos was high (188.7/plate) (Table 4, Fig. 1f, g). Substitution of BA for TDZ in this medium did not significantly affect the number of calli forming embryos but reduced the total yield of mature embryos (87.0/plate).

Table 4. Effect of growth regulators on embryo development and maturation from 'Chancellor' grape embryogenic callus in vitro.

\begin{tabular}{cccccccc}
\hline \multicolumn{2}{c}{ Growth regulator combinations $(\mu \mathrm{M})$} & $\begin{array}{c}\text { AC } \\
(\mathrm{g} / \mathrm{l})\end{array}$ & $\begin{array}{c}\text { Mean number } \\
\text { of calli with } \\
\text { embryos* }\end{array}$ & $\begin{array}{c}\text { Mean number } \\
\text { of embryos per } \\
\text { plate* }\end{array}$ \\
\hline IASP & NOA & BA & TDZ & ABA & & $0.0 \mathrm{~d}$ & $0.0 \mathrm{f}$ \\
\hline 0 & 0 & 0 & 0 & 0 & 0 & $0.7 \mathrm{~cd}$ \\
0 & 0 & 0 & 0 & 0 & 2.5 & $1.0 \mathrm{c}$ & $0.0 \mathrm{f}$ \\
0 & 8 & 1 & 0 & 1 & 0 & $0.0 \mathrm{~d}$ & $0.0 \mathrm{f}$ \\
0 & 8 & 0 & 1 & 1 & 0 & $0.0 \mathrm{~d}$ & $3.7 \mathrm{e}$ \\
0 & 8 & 1 & 0 & 1 & 2.5 & $1.0 \mathrm{c}$ & $11.7 \mathrm{c}$ \\
0 & 8 & 0 & 1 & 1 & 2.5 & $1.0 \mathrm{c}$ & $2.0 \mathrm{e}$ \\
10 & 0 & 1 & 0 & 1 & 0 & $0.3 \mathrm{~d}$ & $0.0 \mathrm{f}$ \\
10 & 0 & 0 & 1 & 1 & 0 & $0.0 \mathrm{~d}$ & $2.7 \mathrm{e}$ \\
10 & 0 & 1 & 0 & 1 & 2.5 & $1.0 \mathrm{c}$ & $7.7 \mathrm{~cd}$ \\
10 & 0 & 0 & 1 & 1 & 2.5 & $1.0 \mathrm{c}$ & $11.7 \mathrm{c}$ \\
10 & 8 & 1 & 0 & 1 & 0 & $4.0 \mathrm{~b}$ & $87.0 \mathrm{c}$ \\
10 & 8 & 0 & 1 & 1 & 0 & $5.3 \mathrm{ab}$ & $188.7 \mathrm{a}$ \\
10 & 8 & 1 & 0 & 1 & 2.5 & $9.7 \mathrm{a}$ & $8.7 \mathrm{a}$ \\
10 & 8 & 0 & 1 & 1 & 2.5 & & \\
\hline
\end{tabular}

*Means followed by the same letter series within a column are not significantly different by DMRT at $\mathrm{p} \leq 0.05$.

When calli were cultured on media with either IASP or NOA alone or when the two growth regulators were combined with $\mathrm{BA}$ or TDZ, ABA and AC, respectively, very low and statistically insignificant embryo counts were observed. Even lower counts were observed when BA was substituted for TDZ (Table 4).

The presence or absence of AC in the media significantly affected embryo development from embryogenic calli of 'Chancellor'. With AC all media had significantly higher numbers of mature embryos than similar treatments without AC. Without growth regulators, up to $10 \%$ of calli developed somatic embryos on media containing AC; none formed when AC was absent (Table 4). When AC was excluded from these media asynchronous embryo development, characterized by the presence of virtually all stages of embryo formation in the cultures, was observed (Fig. 1h). Similar observations were reported by Motoike et al. (2001). The exact role of AC in tissue culture media is not clear, but it has been suggested that it adsorbs potentially inhibitory substances such as phenolics secreted by plant cells, hence stimulating growth in cell cultures (Fribourg et al. 1978, Zhu et al. 1997). 
Embryo germination and subsequent conversion into normally growing plantlets is the most important limiting step in grapevine regeneration by somatic embryogenesis (Gray and Meredith 1992, Goebel-Tourand et al. 1993). Studies to improve plantlet formation from somatic embryos have recommended chilling of embryos for 5 - 20 days at $4^{\circ} \mathrm{C}$ following partial desiccation before germination (Mauro et al. 1986, Gray 1989, Das et al. 2002). However, preliminary trials in this study with a $4^{\circ} \mathrm{C}$ chilling for 5 days after an initial 15 min air drying resulted in very poor germination, heavy callusing and no plantlet formation (data not shown). In studies with Vitis vinifera cvs. 'Muscat seedless', 'Muscat seedless $\times$ Centennial seedless' and 'Sultanina', chilling was found to promote germination of somatic embryos from the cultivar 'Sultanina' only while proving inhibitory to the other two (Trautmann and Burger 1997). These differences in response could be ascribed to genotypic effects.

Table 5. Summary ANOVA for percentage germination of mature somatic embryos from 'Chancellor' grape three weeks after transfer to light.

\begin{tabular}{lllll}
\hline Source of variation & df & Means squares & $F$ & Significance \\
\hline Growth regulator regime (GR) & 2 & 9158.333 & 47.78 & $* * *$ \\
Basal media (BM) & 1 & 1111.111 & 5.80 & $*$ \\
Activated charcoal (AC) & 1 & 19600.000 & 102.26 & $* * *$ \\
GR $\times$ BM interaction & 2 & 452.778 & 2.36 & $n s$ \\
GR $\times$ AC interaction & 2 & 2858.333 & 14.91 & $* * *$ \\
BM $\times$ AC interaction & 1 & 44.444 & 0.23 & $n s$ \\
GR $\times$ BM $\times$ AC interaction & 2 & 52.778 & 0.28 & $n s$ \\
Error & 24 & 191.667 & & \\
\hline
\end{tabular}

$n s:$ Not significant; ${ }^{*}$ Significant at $\mathrm{p} \leq 0.05 ;{ }^{* *}$ Significant at $\mathrm{p} \leq 0.01$;

***Significant at $\mathrm{p} \leq 0.001$.

In typical embryogenesis protocols, embryo germination and conversion to plantlets are two distinct stages, usually achieved under different conditions of media and growth regulators. In the present study, the authors sought to germinate embryos and develop plantlets in a single culture step. Somatic embryo germination, characterized by the rapid expansion of cotyledons, radicle elongation and the synthesis of chlorophyll, was evident in responding cultures ten days after transfer to light (Fig. 1i). Plantlet formation, marked by the emergence of a growing apical shoot tip and the formation of secondary roots from the main tap root, was evident in some germinated embryos within three weeks of transfer to light (Fig. 1j). However, most cultures failed to produce shoot meristems and tended to exhibit an overgrowth of their cotyledons (Fig. $1 \mathrm{k})$. 
Growth regulator regimes, basal media, and AC significantly affected embryo germination but normal plantlet development was only affected by growth regulators and AC (Tables 5, 6). Overall, the inclusion of AC in media significantly reduced the germination capacity of embryos and increased the production of aberrant plantlets. Germination and normal plantlet development was significantly higher for embryos planted on NN medium compared to half strength of MS. The highest germination percentage (100) was achieved in NN medium supplemented with $0.5 \mu \mathrm{M}$ BA $+0.025 \mu \mathrm{M}$ NAA. However, only $35 \%$ of germinated embryos converted into normal growing plantlets. Embryo germination and plantlet formation results also indicated significant interactions between growth regulator regimes and AC treatments, respectively (Tables 5, 6). Analysis of these interactions by linear contrasts revealed a significant interaction between medium $(0.5 \mu \mathrm{M}$ BA $+0.025 \mu \mathrm{M}$ NAA) and the absence of AC which produced higher germination and embryo conversion rates. Plantlets produced from converted embryos were potted, acclimatized and transferred to a greenhouse where they grew normally (Fig. 1m) and some have produced fruit.

Table 6. Summary ANOVA for the number of normal plantlets formed from somatic embryos of 'Chancellor' grape six weeks after transfer to light.

\begin{tabular}{lcccc}
\hline Source of variation & df & Means squares & $F$ & Significance \\
\hline Growth regulator regime (GR) & 2 & 37.528 & 47.78 & $* * *$ \\
Basal media (BM) & 1 & 0.000 & 0.00 & ns \\
Activated charcoal (AC) & 1 & 18.778 & 19.88 & $* * *$ \\
GR $\times$ BM interaction & 2 & 0.0833 & 0.09 & $n s$ \\
GR $\times$ AC interaction & 2 & 6.694 & 7.09 & $* * *$ \\
BM $\times$ AC interaction & 1 & 2.778 & 2.94 & $n s$ \\
GR $\times$ BM $\times$ AC interaction & 2 & 1.028 & 1.09 & $n s$ \\
Error & 24 & 0.944 & & \\
\hline
\end{tabular}

ns: Not significant; ${ }^{*}$ Significant at $\mathrm{p} \leq 0.05 ;{ }^{* *}$ Significant at $\mathrm{p} \leq 0.01 ;{ }^{* * * \text { Significant at }}$ $\mathrm{p} \leq 0.001$.

In conclusion, this study has elucidated an efficient regeneration system based on somatic embryogenesis for the Vitis interspecific hybrid 'Chancellor'.

\section{Acknowledgements}

This research was supported by funds provided by the University of Illinois Agricultural Experimentation Station (UI Research Board Project No. 65-0323). Special thanks to Egerton University, Kenya, for granting leave to first author (RMSM) to carry out this work at The University of Illinois, Any opinions, findings, conclusions, or recommendations are those of the authors and do not necessarily reflect those of the US Department of Agriculture. 


\section{References}

Altamura MM, Cersosimo A, Majoli C and Crespan M (1992) Histological study of embryogenesis and organogenesis from anthers of Vitis rupestris du Lot cultured in vitro. Protoplasma 171: 134-141.

Brooks and Olmo (1997) The Brooks and Olmo Register of Fruit and Nut Varieties. ASHS Press, Alexandria, VA.

Das DK, Reddy MK, Upadhyaya KC and Sopory SK (2002) An efficient leaf-disk culture method for the regeneration via somatic embryogenesis and transformation of grape (Vitis vinifera L.). Plant Cell Reports 20: 999-1005.

Emershad RL and Ramming DW (1994) Somatic embryogenesis and plant development from immature zygotic embryos of seedless grapes (Vitis vinifera L.). Plant Cell Reports 14: 6-12.

Faure O (1990). Embryons somatiques de Vitis rupestris et embryons zygotiques de Vitis sp.: morphologie, histologie, histochimie et developement. Canadian Journal of Botany 68: 2305-2315.

Faure O, Aarrouf J and Nougarede A (1996) Ontogenesis, differentiation and precocious germination in anther-derived somatic embryos of grapevine (Vitis vinifera L.): Proembryogenesis. Annals of Botany 78: 23-28.

Fribourg G, Pedersen M, Landstrom L and Eriksson T (1978) The effect of activated charcoal on tissue cultures: adsorption of metabolites inhibiting morphogenesis. Physiologia Planta. 43: 104-106.

Gianazza E, De ponti P, Scienza A, Villa P and Martinelli L (1992) Monitoring by twodimensional electrophoresis somatic embryogenesis in leaf and petiole explants from Vitis. Electrophoresis 13: 203-209.

Goebel-Tourand I, Mauro M, Sossountzov L, Miginiac E and Deloire A (1993) Arrest of somatic embryo development and the effect of ABA, BAP and zeatin in stimulating plantlet development. Plant Cell, Tiss. Org. Cult. 33: 91-103.

Gray DJ (1989) Effects of dehydration and exogenous growth regulators on dormancy, quiescence and germination of grape somatic embryos. In Vitro Cellular and Developmental Biology 25: 1173-1178.

Gray DJ and Meredith CP (1992) Grape. In: Biotechnology of Perennial Fruit Crops (Eds. Hammerschlag FA and Litz RE), CAB International, Cambridge. pp. 229-262.

Gray DJ and Mortensen JA (1987) Initiation and maintenance of long-term somatic embryogenesis from anthers and ovaries of Vitis longii 'Microsperma'. Plant Cell, Tiss. Org. Cult. 9: 73-80.

Krul WR and Worley JF (1977) Formation of adventitious embryos in callus cultures of 'Seyval', a French hybrid grape. J. Amer. Soc. Hort. Sci. 102: 360-363.

Martinelli L and Gribaudo I (2001) Somatic embryogenesis in grapevine. In: Molecular Biology and Biotechnology of the Grapevine (Ed. Roubelakis-Angelakis KA), Kluwer Academic Publishers, Dordrecht. pp. 327-351.

Martinelli L, Bragagna P, Poletti V and Scienza A (1993) Somatic embryogenesis from leaf and petiole derived callus of Vitis rupestris. Plant Cell Reports 12: 207-210. 
Mauro M, Nef C and Fallot J (1986) Stimulation of somatic embryogenesis and plant regeneration from anther culture of Vitis vinifera cv. 'Cabernet Sauvignon'. Plant Cell Reports 5: 139-144.

Motoike SY, Skirvin RM, Norton MA and Otterbacher AG (2001) Somatic embryogenesis and long term maintenance of embryogenic lines from fox grapes. Plant cell, Tiss. Org. Cult. 66: 121-131.

Mullins MG and Srinivasan C (1976) Somatic embryos and plantlets from an ancient clone of the grapevine (cv. 'Cabernet-Sauvignon') by apomixis in vitro. J. Exp. Botany 27: 1022-1030.

Nakano M, Watanabe $\mathbf{Y}$ and Hoshino Y (2000) Histological examination of callogenesis and adventitious embryogenesis in immature ovary culture of grapevine (Vitis vinifera L.) J. Hort. Sci. and Biotechnol. 75: 154-160.

Nitsch JP and Nitsch C (1969). Haploid plants from pollen grains. Science 163: 85-87

Perl A, Saad S, Sahar N and Holland D (1995) Establishment of long-term embryogenic cultures of seedless Vitis vinifera cultivars - a synergistic effect of auxins and the role of abscissic acid. Plant Sci. 104: 193-200.

Popescu CF (1996). Somatic embryogenesis and plant development from anther culture of Vitis vinifera (L). Plant Growth Regulation 20: 75-78.

Robacker C (1993) Somatic embryogenesis and plant regeneration from muscadine grape leaf explants. Hort. Sci. 28: 53-55.

Salunkhe CK, Rao PS and Mhatre M (1997) Induction of somatic embryogenesis and plantlets in tendrils of Vitis vinifera L. Plant Cell Reports 17: 65- 67.

SAS Institute Inc. (1990). Cary, North Carolina, USA.

Srinivasan C and Mullins MG (1980) High frequency somatic embryo production from unfertilized ovules of grapes. Scientia Horticult. 13: 245-252.

Staba JE (1969). Plant tissue culture as a technique for the phytochemist. Recent Advances in Phytochemistry 2: 80.

Stamp JA and Meredith CP (1988) Proliferative somatic embryogenesis from zygotic embryos of grapevine. J. Amer. Soc. Hort. Sci. 113: 941-945.

Trautmann IA and Burger P (1997) Prerequisites for high frequency germination of somatic embryos of Vitis vinifera. Acta Horticult. 447: 95-100.

Zhu YM, Hoshino Y, Nakano M, Takahashi E and Mii M (1997) Highly efficient system of plant regeneration from protoplasts of grapevine (Vitis vinifera L.) through somatic embryogenesis by using embryogenic cultures and activated charcoal. Plant Sci. 123: 151-157. 